\title{
Electrical properties of metal-ferroelectric-insulator-semiconductor field effect transistors (MFIS-FETs) using the polyvinylidene fluoride-trifluoroethylene (P(VDF-TrFE)) $/ \mathrm{ZrO}_{2} / \mathrm{Si}$ structure
}

\author{
Gwang-Geun LEE, Hui-Seong HAN, Yun-Soo CHOI ${ }^{*}$ and Byung-Eun PARK ${ }^{\dagger}$ \\ Department of Electrical and Computer Engineering, University of Seoul, \\ 90 Jeonnong-dong, Dongdaemun-gu, Seoul 130-743, Korea \\ *Department of Geo-Informatics, University of Seoul, 90 Jeonnong-dong, Dongdaemun-gu, Seoul 130-743, Korea
}

\begin{abstract}
In this study, we fabricated the n-channel metal-ferroelectric-insulator-semiconductor field effect transistors (MFIS-FETs) using an Au/polyvinylidene fluoride-trifluoroethylene $\mathrm{P}(\mathrm{VDF}-\mathrm{TrFE}) / \mathrm{ZrO}_{2} / \mathrm{Si}(100)$ structures. The $\mathrm{ZrO}_{2}$ thin film had the equivalent

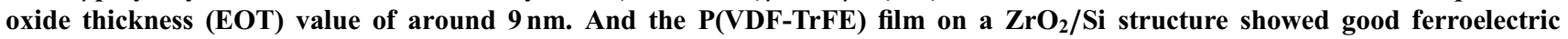
property with memory window width of $2.5 \mathrm{~V}$ for a bias voltage sweeping of $\pm 7 \mathrm{~V}$. The leakage current density of this MFIS structure showed very excellent insulation property with about $9 \times 10^{-8} \mathrm{~A} / \mathrm{cm}^{2}$ at $5 \mathrm{~V}$. Based on these results, we fabricated and investigated MFIS-FETs with ferroelectric polymer $\mathrm{P}(\mathrm{VDF}-\mathrm{TrFE})$ film and $\mathrm{ZrO}_{2}$ buffer layer. The memory window width and on/off ratio of the MFIS-FET was about $4.5 \mathrm{~V}$ and $10^{3}$, respectively. These results predicted that the P(VDF-TrFE) thin film would be useful for the realization of 1-transistor type ferroelectric memory.

(C2010 The Ceramic Society of Japan. All rights reserved.
\end{abstract}

Key-words : P(VDF-TrFE), Memory window, MFIS-FET, $\mathrm{ZrO}_{2}$

[Received July 9, 2010; Accepted August 19, 2010]

\section{Introduction}

Ferroelectric gate field-effect transistors (Fe-FETs) promise to be future nonvolatile memories, which boasts of nondestructive readout, high speed operation, high density integration and low power consumption as its advantages. ${ }^{1), 2)}$ Conventional researches on the Fe-FETs have focused on utilizing inorganic ferroelectric materials such as $(\mathrm{Bi}, \mathrm{La})_{4} \mathrm{Ti}_{3} \mathrm{O}_{12}(\mathrm{BLT}), \mathrm{Pb}(\mathrm{Zr}, \mathrm{Ti}) \mathrm{O}_{3}$ (PZT) and $\mathrm{SrBi}_{2} \mathrm{Ta}_{2} \mathrm{O}_{9}$ (SBT). ${ }^{3)-5)}$ Using these materials, however, Fe-FETs encounter severe problems related with interfacial reaction such as inter-diffusion commonly due to the high crystallization of inorganic ferroelectric materials. ${ }^{6}$ ) To solve these problems, using the polymer ferroelectric materials such as polyvinylidene fluoride (PVDF) and $\mathrm{P}(\mathrm{VDF}-\mathrm{TrFE})$ might be an effective method because implementing a process below $200^{\circ} \mathrm{C}$ is more effective than when using inorganic ferroelectric materials.

PVDF and its copolymer P(VDF-TrFE) are representative polymers that have been intensively studied for a wide range of applications, including nonvolatile memory in organic electronic devices, such as electro-optics, electromechanical transducers, and biomedical applications. ${ }^{7), 8)}$ The peculiar properties of PVDF are intimately associated with its crystalline phases $(\alpha$, $\beta, \gamma$, and $\delta$ ), wherein $\beta$-phase crystalline exhibits the strongest ferroelectricity among the four crystalline phases. ${ }^{9}$ Its copolymer $\mathrm{P}(\mathrm{VDF}-\mathrm{TrFE})$ is one way of easily obtaining $\beta$-phase crystalline through heat treatment between the curie transition temperature $\left(T_{\mathrm{c}}\right)$ and the melting temperature $\left(T_{\mathrm{m}}\right) \cdot{ }^{10)} \mathrm{P}(\mathrm{VDF}-\mathrm{TrFE})$ has a large spontaneous polarization of $\sim 10 \mu \mathrm{C} / \mathrm{cm}^{2}$, excellent polarization stability, and switching time as short as $0.1 \mathrm{~ms} .^{11)-13)}$ Furthermore, $\mathrm{P}(\mathrm{VDF}-\mathrm{TrFE})$ does not require high-temperature processing, and has outstanding chemical stability and low fabrication cost.

\footnotetext{
Corresponding author: B.-E. Park; E-mail: pbe@uos.ac.kr
}

In this work, we investigated $\mathrm{P}(\mathrm{VDF}-\mathrm{TrFE})$ films as a ferroelectric layer for Fe-FETs. Our previous experiments on a metal-ferroelectric-insulator-semiconductor (MFIS) structures with $\mathrm{P}(\mathrm{VDF}-\mathrm{TrFE})$ film and $\mathrm{ZrO}_{2}$ buffer layer proved the possibility of ferroelectric memory. However, the ferroelectric property such as drain current-gate voltage $\left(I_{\mathrm{D}}-V_{\mathrm{G}}\right)$ characteristic of this MFIS-FETs shows a tendency to shift of plus voltage direction. ${ }^{14)}$ It seems that the electrical properties of the $\mathrm{ZrO}_{2} / \mathrm{Si}$ structures were not sufficient. To make this solution work, we should have fabricated to adequate buffer layers with good electrical properties. Although high- $k \mathrm{ZrO}_{2}$ needs to be processed in high temperature, it could be used as a very effective insulator for microelectronics and a buffer insulator for metal-insulatorferroelectric-semiconductor structure. In another our attempt with $\mathrm{LaZrO}_{x}$ buffer layers, there were a lot of difficulties in repeatability with good electrical properties. ${ }^{15)}$ Thus, we fabricated the $\mathrm{P}(\mathrm{VDF}-\mathrm{TrFE}) / \mathrm{ZrO}_{2} / \mathrm{Si}(100)$ structures with good electrical properties. On the basis of these results, we fabricated the MFIS-FETs and measured their electrical properties.

\section{Experiment}

The $\mathrm{ZrO}_{2}$ thin film layer, with typical film thickness at about $38 \mathrm{~nm}$, was prepared on silicon wafers using the sol-gel wetchemical method. The sol-gel solution for $\mathrm{ZrO}_{2}$ was synthesized using zirconium propoxide $\left[\mathrm{Zr}\left(\mathrm{OCH}\left(\mathrm{CH}_{3}\right)_{2}\right)_{4}\right]$ and 2-methoxyethanol $\left(\mathrm{CH}_{3} \mathrm{OCH}_{2} \mathrm{CH}_{2} \mathrm{OH}\right)$. P-type $\mathrm{Si}(100)$ with a resistance of $1-20 \Omega \cdot \mathrm{cm}$ was used as a substrate. After cleaning the substrate through the standard process, the $\mathrm{ZrO}_{2}$ solution was spin-coated at $4000 \mathrm{rpm}$ for $25 \mathrm{~s}$, and then dried at $400^{\circ} \mathrm{C}$ for $10 \mathrm{~min}$. The dried $\mathrm{ZrO}_{2}$ thin film was finally annealed at $650^{\circ} \mathrm{C}$ for $30 \mathrm{~min}$. The $\mathrm{P}(\mathrm{VDF}-\mathrm{TrFE})$ ferroelectric polymer containing VDF (75 mol \%) and TrFE $(25 \mathrm{~mol} \%)$ was used as a ferroelectric material. The P(VDF-TrFE) copolymer powders were dissolved in a dimethylformide (DMF) solvent and the P(VDF-TrFE) film 


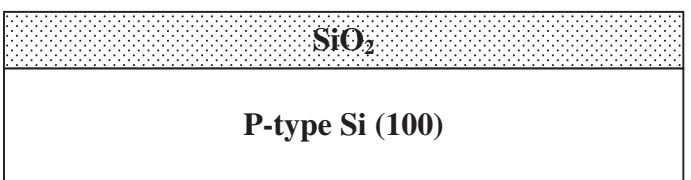

(a)

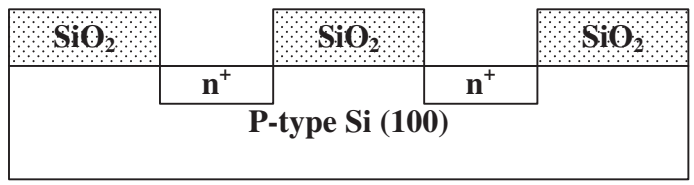

(b)

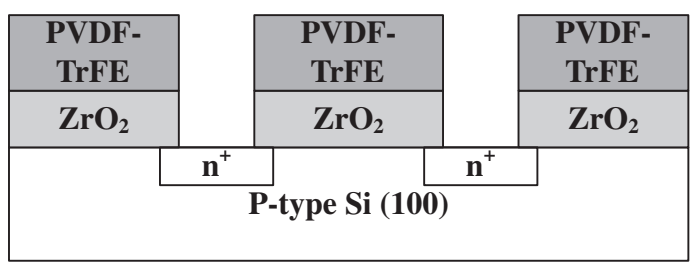

(c)

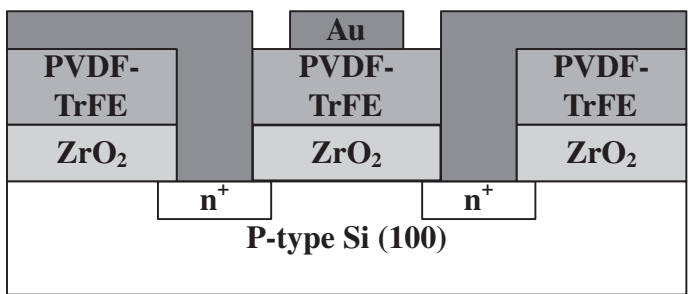

(d)

Fig. 1. Schematic of MFIS-FETs fabrication: (a) thermal oxidation, (b) PSG diffusion, (c) $\mathrm{ZrO}_{2}$ and $\mathrm{P}(\mathrm{VDF}-\mathrm{TrFE})$ deposition, and (d) $\mathrm{Au}$ electrode metallization.

was spin-coated on the $\mathrm{ZrO}_{2} / \mathrm{Si}$ structure. The $\mathrm{P}(\mathrm{VDF}-\mathrm{TrFE})$ film was heat-treated at $140^{\circ} \mathrm{C}$ for $60 \mathrm{~min}$ on a hot-plate to remove residual solvents and improve its crystallinity. The typical film thickness was $60 \mathrm{~nm}$. Gold electrodes were formed through thermal evaporation. The capacitance-voltage $(C-V)$ and current density-voltage $(J-V)$ characteristics were measured using HP 4280 and HP $4155 \mathrm{C}$, respectively. Based on the electrical properties of an MFIS capacitor, we fabricated the n-channel MFIS-FETs. Definition of the source and drain region was performed through the phosphorus glass (PSG) diffusion at $1050^{\circ} \mathrm{C}$ for $45 \mathrm{~s}$ in rapid thermal annealing (RTA). And then, the $\mathrm{ZrO}_{2}$ and $\mathrm{P}(\mathrm{VDF}-\mathrm{TrFE})$ thin film were spin-coated in sequence on the substrate and the $\mathrm{ZrO}_{2}$ film, respectively. The deposition condition for the $\mathrm{ZrO}_{2}$ and $\mathrm{P}(\mathrm{VDF}-\mathrm{TrFE})$ thin film was identical to those in an MFIS structure. For contact holes in the drain and source, the $\mathrm{ZrO}_{2}$ layer and $\mathrm{P}(\mathrm{VDF}-\mathrm{TrFE})$ thin film were etched by buffer oxide etch (BOE) and $\mathrm{O}_{2}$ plasma at 150 mTorr and $100 \mathrm{~W}$ for $30 \mathrm{~s}$. Au electrodes were thermally evaporated on the surface of the P(VDF-TrFE) film, then, to define the drain/source contact pads and gate electrode, unnecessary Au residuals were removed using an $\mathrm{Au}$ etching solution. The schematic of the MFIS-FETs fabrication process is shown in Fig. 1. The channel length and width of the finally fabricated MFIS-FETs were 30 and $60 \mu \mathrm{m}$, respectively. The $I_{\mathrm{D}}-V_{\mathrm{D}}$ (drain current-drain voltage) and $I_{\mathrm{D}}-V_{\mathrm{G}}$ (drain current-gate voltage) were also measured using HP 4155C. All measurements were performed at room temperature in air ambient.

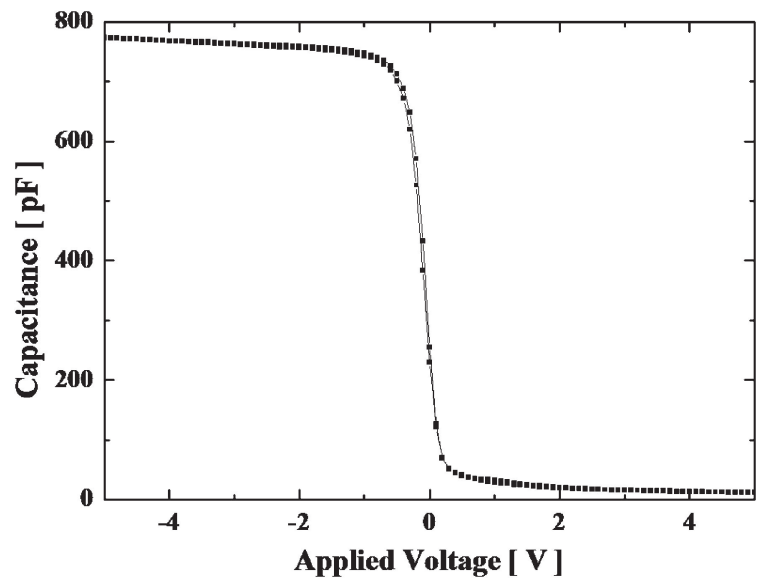

(a)

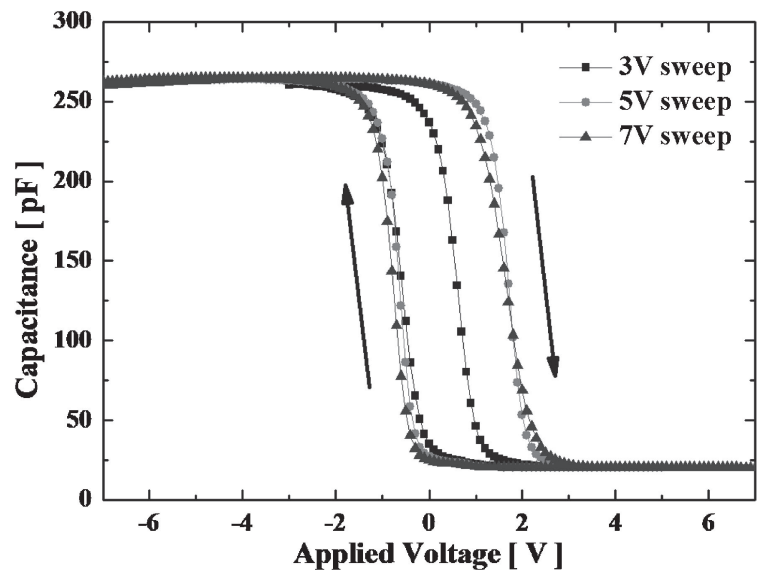

(b)

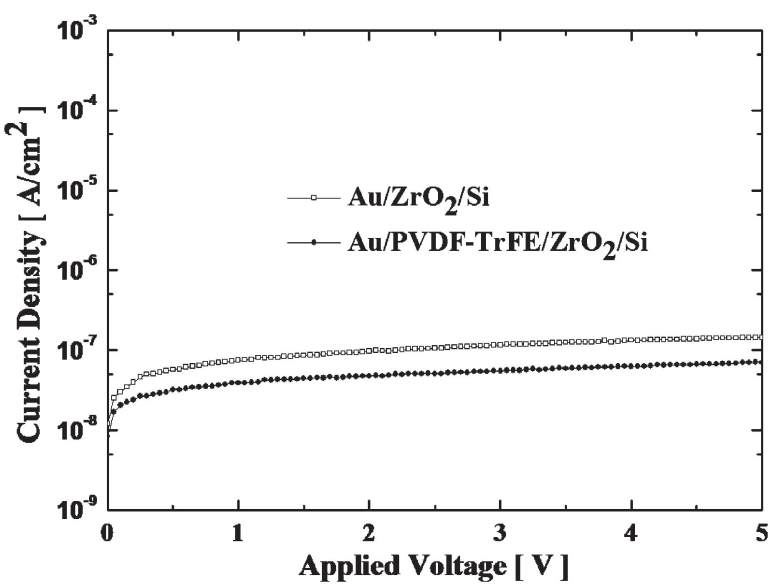

(c)

Fig. 2. $C-V$ characteristics of (a) $\mathrm{Au} / \mathrm{ZrO}_{2} / \mathrm{Si}$ and (b) $\mathrm{Au} / \mathrm{P}(\mathrm{VDF}-$ $\mathrm{TrFE}) / \mathrm{ZrO}_{2} / \mathrm{Si}$ structure and (c) $J-V$ characteristics.

\section{Results and discussions}

First, we investigated the electrical properties of the $\mathrm{Au} / \mathrm{ZrO}_{2} /$ $\mathrm{Si}$ and $\mathrm{Au} / \mathrm{P}(\mathrm{VDF}-\mathrm{TrFE}) / \mathrm{ZrO}_{2} / \mathrm{Si}$ structures. Figures 2 (a) and 2(b) reveal the $C-V$ characteristics of the $\mathrm{Au} / \mathrm{ZrO}_{2} / \mathrm{Si}$ and $\mathrm{Au} /$ $\mathrm{P}(\mathrm{VDF}-\mathrm{TrFE}) / \mathrm{ZrO}_{2} / \mathrm{Si}$ structures. The $C-V$ measurements were carried out at sweep voltage $\pm 5 \mathrm{~V}$ at $1 \mathrm{MHz}$. It is worth noting that no hysteresis loop was observed, as shown in Fig. 2(a). This 


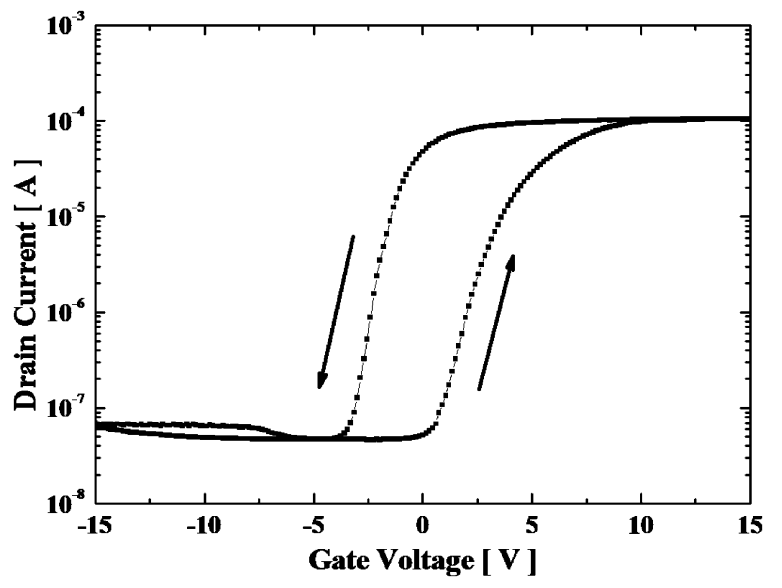

Fig. 3. $I_{\mathrm{D}}-V_{\mathrm{G}}$ characteristics of the MFIS-FETs.

result indicated that charge injection or ion drift effects are negligibly small. As derived from the accumulation capacitance, the equivalent oxide thickness (EOT) value was $9 \mathrm{~nm}$, and the dielectric constant was calculated at 15 . In order to distribute bias voltage enough to the ferroelectric layer, the small EOT value was desirable for a buffer insulator in an MFIS-FET. However, in this study, it shows relatively large EOT value, which may be attributed to the existence of an interfacial $\mathrm{SiO}_{2}$ layer, was formed in a dry oxygen atmosphere during the annealing process. The calculated thickness of interfacial $\mathrm{SiO}_{2}$ layer was about $5 \mathrm{~nm}$. The $C-V$ plots in Fig. 2(b) show clockwise hysteresis loops, as indicated by the arrows, which points to the ferroelectric behavior of the $\mathrm{P}(\mathrm{VDF}-\mathrm{TrFE})$ film. This study also revealed that the memory window widths, saturated at the sweep voltage of $\pm 5 \mathrm{~V}$, gradually increased with the applied voltage. The memory window width of the $\mathrm{Au} / \mathrm{P}(\mathrm{VDF}-\mathrm{TrFE}) / \mathrm{ZrO}_{2} / \mathrm{Si}$ structure was about $2.5 \mathrm{~V}$ at the sweep voltage of $\pm 7 \mathrm{~V}$. To verify whether the memory window of the $C-V$ characteristics originates from the ferroelectric polarization reversal or ion drift, the scanning speed of the applied voltage varied from 0.1 to $0.5 \mathrm{~V} / \mathrm{s}$. As a result, it revealed that the memory window of the $C-V$ characteristics did not change. Therefore, the memory window of the $\mathrm{Au} / \mathrm{P}(\mathrm{VDF}-\mathrm{TrFE}) / \mathrm{ZrO}_{2} / \mathrm{Si}$ structure indicated the ferroelectricity of the P(VDF-TrFE) film. By using the accumulation capacitance determined from the $C-V$ curve of $\mathrm{Au} / \mathrm{P}(\mathrm{VDF}-$ $\mathrm{TrFE}) / \mathrm{ZrO}_{2} / \mathrm{Si}$ structure, the dielectric constant of the P(VDF$\mathrm{TrFE}$ ) film is calculated to be about 10 . And we already verified the $P-E$ characteristics of $P(V D F-T r F E)$ thick film on the MFM structure (not shown this paper). Usually, $\mathrm{P}(\mathrm{VDF}-\mathrm{TrFE})$ thin film above $100 \mathrm{~nm}$ in the MFM structure shows the good ferroelectric properties. In this study, however, 60-nm-thick P(VDF-TrFE) film on this $\mathrm{ZrO}_{2} / \mathrm{Si}(100)$ structure also showed the good ferroelectric properties.

Figure 2(c) shows the current densities versus the appliedvoltage characteristics of the $\mathrm{Au} / \mathrm{ZrO}_{2} / \mathrm{Si}$ and $\mathrm{Au} / \mathrm{P}(\mathrm{VDF}-$ $\mathrm{TrFE}) / \mathrm{ZrO}_{2} / \mathrm{Si}$ structures. The current leakage density of the $\mathrm{Au} / \mathrm{ZrO}_{2} / \mathrm{Si}$ and $\mathrm{Au} / \mathrm{P}(\mathrm{VDF}-\mathrm{TrFE}) / \mathrm{ZrO}_{2} / \mathrm{Si}$ structure were approximately $9 \times 10^{-7}$ and $9 \times 10^{-8} \mathrm{~A} / \mathrm{cm}^{2}$ at applied voltage $5 \mathrm{~V}$, respectively. This proves that the fabricated $\mathrm{ZrO}_{2}$ film has very excellent insulation property as compared with previous results. ${ }^{14)}$

Figure 3 shows the $I_{\mathrm{D}}-V_{\mathrm{G}}$ characteristics of the MFIS-FETs. The applied gate voltage sweep range was from -15 to $+15 \mathrm{~V}$, and the drain voltage was fixed at $2 \mathrm{~V}$. In this measurement, the hysteresis loop was obtained with a counter-clockwise trace

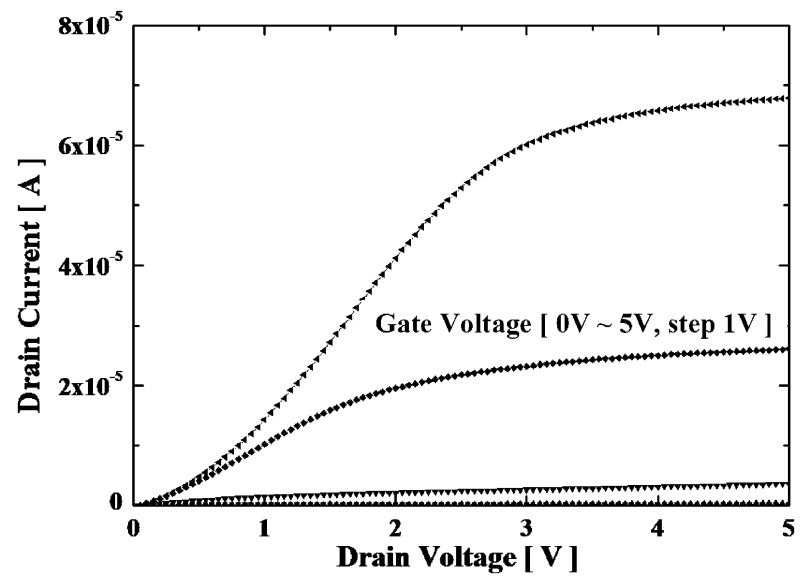

Fig. 4. $I_{\mathrm{D}}-V_{\mathrm{D}}$ characteristics of the MFIS-FETs.

which is the direction opposite to the $C-V$ curves, as indicated by the arrows because of the ferroelectricity of the P(VDF-TrFE) films and the n-channel. The memory window width was about $4.5 \mathrm{~V}$ because as the bias increases, the value of memory window is increased originally until the certain limit. And the drain current ratio of the on- and off-states was about $10^{3}$ at the bias gate voltage, $V_{\mathrm{G}}=1.0 \mathrm{~V}$.

Figure 4 shows the $I_{\mathrm{D}}-V_{\mathrm{D}}$ characteristics of the MFIS-FETs. The step voltages of $1 \mathrm{~V}$ from 0 to $5 \mathrm{~V}$ and the sweeping voltages from 0 to $5 \mathrm{~V}$ were applied to the gate electrodes and drain of MFIS-FETs. The curves show typical characteristics of the n-channel FETs like metal-oxide-semiconductor field effect transistor (MOSFET). As the gate voltage increased, the drain current $I_{\mathrm{D}}$ increased which implies that $\mathrm{P}(\mathrm{VDF}-\mathrm{TrFE})$ films function as a gate dielectric layer. The $I_{\mathrm{D}}$ value in Fig. 3 at $V_{\mathrm{D}}=2 \mathrm{~V}$ and $V_{\mathrm{G}}=5 \mathrm{~V}$ is about 30 ( $V_{\mathrm{G}}$ increases) and 100 ( $V_{\mathrm{G}}$ decreases) $\mu \mathrm{A}$, but the $I_{\mathrm{D}}$ value in Fig. 4 at $V_{\mathrm{D}}=2 \mathrm{~V}$ and $V_{\mathrm{G}}=5 \mathrm{~V}$ is about $40 \mu \mathrm{A}$. As mentioned above Fig. 2(c), the fabricated $\mathrm{ZrO}_{2}$ film has very excellent insulation property, thus the phenomenon is not caused by the leakage current, it is just caused by the polarization direction.

\section{Conclusion}

After fabricating MIS, MFIS and MFIS-FET structures, this study observed no hysteretic characteristic in the $C-V$ curve of the $\mathrm{Au} / \mathrm{ZrO}_{2} / \mathrm{Si}$ structure, but observed a hysteresis loop in the $C-V$ curve of the MFIS structure due to the ferroelectricity of the P(VDF-TrFE) film. The memory window width of the Au/ $\mathrm{P}(\mathrm{VDF}-\mathrm{TrFE}) / \mathrm{ZrO}_{2} / \mathrm{Si}$ structure was about $2.5 \mathrm{~V}$ at the bias sweep range of $\pm 7 \mathrm{~V}$, and the leakage current density was about $9 \times 10^{-8} \mathrm{~A} / \mathrm{cm}^{2}$ at $5 \mathrm{~V}$. Finally, this study also fabricated an n-channel MFIS-FETs with a $\mathrm{P}(\mathrm{VDF}-\mathrm{TrFE}) / \mathrm{ZrO}_{2} / \mathrm{Si}$ structure with an $I_{\mathrm{D}}-V_{\mathrm{D}}$ characteristic at a high drain current of about $0.1 \mathrm{~mA}$ at the gate voltage of $5 \mathrm{~V}$. The $I_{\mathrm{D}}-V_{\mathrm{G}}$ characteristic of the fabricated MFIS-FETs showed a hysteresis loop due to the ferroelectric nature of the $\mathrm{P}(\mathrm{VDF}-\mathrm{TrFE})$ films with a memory window width of about $4.5 \mathrm{~V}$.

Acknowledgment This work was supported by the Korea Science and Engineering Foundation (KOSEF) grant funded by the Korean government (MEST) (No. R01-2007-000-11985-0).

\section{References}

1) D. Bondurant and F. Gnadinger, IEEE Spectrum, 26, 30-33 (1989). 
2) J. T. Evans and R. Womack, IEEE J. Solid-State Circuits, 23, 1171-1175 (1988).

3) Y. U. Song, J. S. Park, J. W. Yoon, G. G. Lee, B. E. Park, C. J. Kim, Y. S. Choi and J. H. Koh, Integr. Ferroelectr., 84, 203210 (2006).

4) S. Sakai and R. Ilanovan, IEEE Electron Device Lett., 25, 369371 (2004).

5) S. M. Yoon, E. Tokumitsu and H. Ishiwara, IEEE Electron Device Lett., 20, 229-231 (1999).

6) B. E. Park and H. Ishiwara, Appl. Phys. Lett., 82, 1197-1199 (2003).

7) H. Kawai, J. Appl. Phys., 8, 975-976 (1969).

8) J. G. Bergman, J. H. McFee and G. R. Crane, Appl. Phys. Lett.,
18, 203-205 (1971).

9) T. Furukawa, Phase Transitions, 18, 143-211 (1989).

10) K. Koga and H. Ohigashi, J. Appl. Phys., 59, 2142-2150 (1986).

11) T. Furukawa, M. Date, M. Ohuchi and A. Chiba, J. Appl. Phys., 56, 1481-1486 (1984).

12) T. Furukawa, Ferroelectrics, 57, 63-72 (1984).

13) A. Konno, K. Shiga, H. Suzuki, T. Koda and S. Ikeda, Jpn. J. Appl. Phys., 39, 5676-5678 (2000).

14) G. G. Lee and B. E. Park, J. Korean Phys. Soc., 56, 1484-1487 (2010).

15) H. S. Han, H. S. Jeon, G. G. Lee, K. J. Kim and B. E. Park, J. Korean Phys. Soc., 55, 898-901 (2009). 